\title{
PLANT PROTECTION AS A CONSEQUENCE OF AN ANT-MEMBRACID MUTUALISM: INTERACTIONS ON GOLDENROD (SOLIDAGO SP.) ${ }^{1}$
}

\author{
Frank J. MESSINA \\ Section of Ecology and Systematics, Cornell University, Ithaca, NY 14853 USA
}

\begin{abstract}
In central New York, two chrysomelid beetles, Trirhabda virgata and T. borealis, frequently cause severe defoliation of tall goldenrod, Solidago altissima. This plant is also the primary host of Publilia concava (Membracidae), a sap-feeding treehopper that is tended by ants, especially Formica spp. Staged encounters indicate that Formica ants attack adult Trirhabda beetles on goldenrod stems bearing membracids. Such stems escape defoliation by Trirhabda, and show greater mean height increment and seed production than their nearest neighbors without ants. The degree of plant protection depends on the duration of Formica presence. During Trirhabda outbreaks, only stems bearing Formica ants for most of the season are likely to produce flowers and seeds. While Formica ants do not exclude Trirhabda larvae from goldenrod stems, they do deter feeding; plants with Formica ants experience significantly less defoliation by larvae than neighboring stems without ants. Two smaller, less aggressive ant species (Prenolepis imparis and Myrmica sp.) do not affect either larval or adult beetle densities.
\end{abstract}

Key words: ants; Formica; herbivory; Homoptera; host plant; mutualism; New York; old field; Publilia; Solidago; Trirhabda.

\section{INTRODUCTION}

Ants often form mutualistic relationships with plants (Janzen 1966, Bentley 1977) and with Homoptera that excrete honeydew (Way 1963). Plants and Homoptera typically supply nutrients to ant foragers; extrafloral nectar and insect honeydew represent the "only stationary and immediately renewable" food source for many ant species (Carroll and Janzen 1973). In turn, ants protect associated plants and insects from their natural enemies. Certain myrmecophilous plants and Homoptera show a loss or reduction of intrinsic defense mechanisms (Rehr et al. 1973, Nault et al. 1976, Wood 1977, 1979). Ant foragers have been observed to repel the potential herbivores of plants and the predators and parasitoids of associated insects (ElZiady and Kennedy 1956, Janzen 1967, Pierce and Mead 1981). If ants tending Homoptera are simply aggressive toward insects having certain general characteristics (falling within a particular size range or having certain movement patterns), then they would exclude not only enemies of Homoptera, but also other herbivores from homopteran host plants. Plants bearing ant-Homoptera associations might then experience reduced herbivore damage, as plants bearing extrafloral nectaries do (Carroll and Janzen 1973). In this paper, I focus on such a "secondary" effect of the ant-Homoptera mutualism by examining the role of Formica ants in affecting herbivory of tall goldenrod, Solidago altissima. While mutualistic relationships in temperate regions have been receiving in-

\footnotetext{
1 Manuscript received 26 November 1980; accepted 2 April 1981.

2 Address correspondence to: Department of Entomology, Comstock Hall, Cornell University, Ithaca, NY 14853 USA.
}

creased attention recently (Tilman 1978, Inouye and Taylor 1979, Pierce and Mead 1981), most studies have examined the consequences of these interactions for only the mutualists themselves.

In central New York, the membracid, Publilia concava, forms aggregations of nymphs and adults at the base of $S$. altissima leaves. Aggregations are tended by several ant species in a mutualistic relationship (McEvoy 1977). Two leaf-chewing beetles, Trirhabda virgata and $T$. borealis (Chrysomelidae), are the dominant herbivores of goldenrod in this area, accounting for 70-95\% of all arthropod individuals and biomass in goldenrod stands (Evans 1980). Both larvae and adults can occur at densities exceeding 35 individuals per stem and can cause complete defoliation. This study examines whether ants exclude Trirhabda from stems with membracids, and what effect such exclusion might have on the defoliation, growth, and seed production of the host plant.

\section{Phenologies of beetles and membracids}

Publilia concava and Trirhabda spp. occur on Solidago for most of the plant's growing season (Fig. 1). Beetle larvae hatch from overwintered eggs at the base of the plants in early May, and immediately begin feeding on the leaves. Overwintered membracid adults appear shortly thereafter, but do not settle onto hosts and begin oviposition until late May (McEvoy 1977). Eggs are laid on the underside of leaves, usually on stems surrounding Formica ant mounds, even though non-Formica ants may tend the aggregations. The female membracid remains with her egg mass, sometimes up to $25 \mathrm{~d}$, apparently to stimulate continuous ant attendance before and after egg hatch (McEvoy 1977). After egg hatch, the adult females move to 


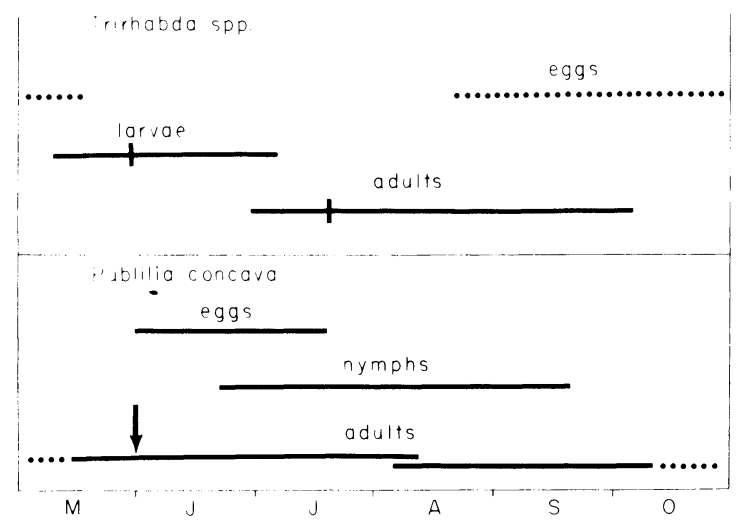

Fig. 1. Phenology of Publilia concava and Trirhabda spp. Arrow indicates typical onset of ant attendance. Vertical bars indicate maximum densities of Trirhabda larvae and adults. Dotted line indicates overwintering stage

oviposit at a new site; this causes an overlapping of membracid broods as the season progresses. Beetle larvae and ant-tended membracid adults are present for 3-4 wk until late June (Fig. 1), when most larvae pupate in the soil. Most adult beetles appear in midJuly (Messina and Root 1980), recolonize the goldenrod stems, and persist along with the developing membracid broods for the remainder of the season (Fig. 1). Thus ants tending the stationary membracids would encounter Trirhabda larvae in June and Trirhabda adults from July to September.

\section{Methods}

This research was conducted in an old field on the Whipple Farm, $8 \mathrm{~km}$ northeast of Ithaca, New York. The site was abandoned as a hay field in 1970. Goldenrod occurred at densities of $50-65$ stemıs $/ \mathrm{m}^{2} ; 64 \%$ of all Solidago stems were $S$. altissima (Messina and Root 1980). Ten to 15 distinctive mounds formed by Formica ants were scattered through the field. Formica colonies were composed of either $F$. fusca alone or of $F$. fusca and its slave maker, F. (Raptiformica) rubicunda.

I located all the stems with ants and membracids around six Formica mounds in late June and early July 1978. Each stem was marked by a numbered stake placed next to it, and 45 marked stems and their nearest conspecific neighbors without ants and membracids were censused biweekly until late August. A marked stem and its neighbors were always within 30 $\mathrm{cm}$ of each other, and, since $S$. altissima reproduces vegetatively, the stems compared were usually from the same clone (as ascertained by the phenotypic similarity and spatial configuration of stems).

In each census, I recorded the number of Trirhabda per stem and stem height for each marked stem and its five nearest neighbors. For each marked stem, I also recorded the presence or absence of ants and the number of membracid nymphs and adults. In late September and early October 1978, I clipped and bagged the inflorescences of each marked stem and its three nearest neighbors. Seeds were fully formed at this time but had not yet dispersed. The involucres per inflorescence were counted in the laboratory, and a few (three to five) involucres on each inflorescence were dissected to determine the number of seeds per involucre. The latter quantity was essentially invariant within an inflorescence.

Interactions between Trirhabda adults and ants were observed in staged encounters on several dates from July to September 1978. Beetles captured in a sweep net were released singly at the base of a stem with a known number of ants or with no ants. I monitored beetle and ant behavior until the beetle left the stem or $300 \mathrm{~s}$ had elapsed. A different beetle was used in each of the 155 trials conducted on 31 stems ( 17 stems with Formica ants, three with other ant species, and 11 with no ants).

In 1979, 36 stems were marked near five Formica mounds. Stems were censused and seed production was estimated as in 1978, except only a single nearest neighbor was used in the comparisons. Also, in 1979, censuses were conducted during the entire period of membracid occurrence, from 31 May to 22 September.

I measured the amount of leaf tissue eaten by Trirhabda larvae in June 1979. In an old field adjacent to the study site, I located 40 stems with Formica by using random grid coordinates, and recorded the number of ants and membracids on each. For each antmembracid stem and its nearest neighbor, I recorded stem height, the number of Trirhabda larvae per stem, and mean leaf area. To determine leaf area, the three leaves closest to a point on the stem (set at threefourths of the full height of the stem) were removed and photocopied onto paper for which the mass : area relationship was known. Leaf images were cut out of the paper, weighed on a Mettler balance, and masses were converted into area.

\section{RESUlts}

\section{Fidelity and identity of tending ants}

Marked stems were divided into three categories in each census: bearing Formica ants, bearing smaller ants, and abandoned by ants (these stems were eventually abandoned by membracids as well). Most stems marked in 1978 bore Formica ants on all censuses from 30 June to 25 August (Table 1). In 1979, however, a large fraction of marked stems was abandoned soon after the first census on 31 May (Table 1). I was able to use this variability in ant fidelity as a "natural experiment" to determine the fate of goldenrod stems bearing ants for varying lengths of time. In both years, few membracid aggregations were tended by the small ants, Prenolepis imparis or Mvrmica sp. 


\section{Exclusion of adult beetles by Formica}

On each census in 1978, significantly fewer beetles were found on stems with Formica than on their nearest neighbors without ants (Fig. 2, Wilcoxon signed-ranks test). Smaller ants, however, did not significantly reduce beetle densities on the stems they tended (Wilcoxon signed-ranks test), nor were there significant differences in beetle density on abandoned stems and their neighbors; these two categories were accordingly combined (Fig. 2), and will be considered together for the remainder of the paper. As shown in Fig. 2, beetle density on stems with Formica ants was also fairly constant over the season, perhaps reflecting an equilibrium between beetle colonization and ant discovery. Density curves for the other stems, however, simply reflect seasonal changes in the Trirhabda population at large (Messina and Root 1980).

On the census dates in 1979 when adult beetles were present, beetle density was again significantly reduced by the presence of Formica. For instance, on $20 \mathrm{July}$, the mean number of beetles on neighboring stems without ants was over seven times higher than the mean number on stems with Formica (3.7 \pm 0.9 ants/ stem vs. $0.5 \pm 0.2 \mathrm{ants} / \mathrm{stem}, P<.05$, Wilcoxon signed-ranks test). Also, as in 1978 , beetle density on abandoned stems or stems bearing smaller ants was indistinguishable from beetle density on their neighbors that had never borne ants.

It is unlikely that the reduction in beetle density on stems with Formica ants could have been due to the activities of the membracids themselves, since membracids did not affect beetle densities on stems with smaller ants. Further evidence that membracids do not inhibit beetle colonization is provided by examination of those few occasions ( 16 times in the $2 \mathrm{yr}$ ) when a censused stem was abandoned by ants but not by membracids. Beetle densities on such stems $(1.7 \pm 0.5$ beetles/stem, $n=16$ ) were not different from those on their neighbors $(1.1 \pm 0.3$ beetles/stem, Wilcoxon signed-ranks test).

In the staged encounters, beetles released at the base of goldenrod stems typically oriented upward and climbed the plant. In 49 of 70 trials on stems with no ants or with non-Formica ants, the beetles crawled
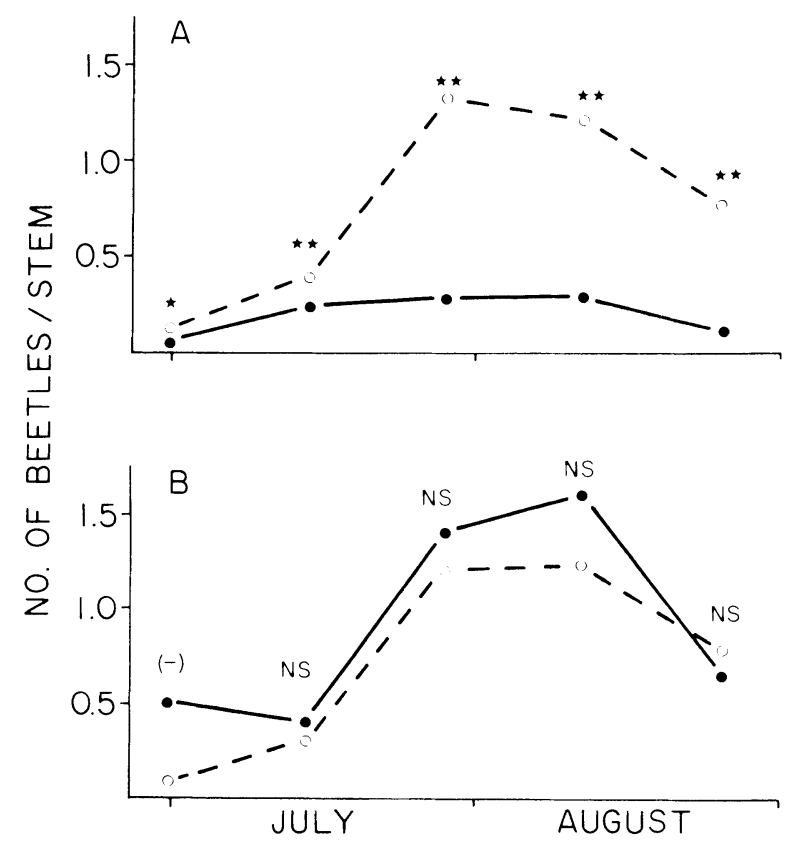

FIG. 2. Comparison of mean 1978 adult beetle density on marked stems (solid lines and closed circles) and their nearest unattended neighbors (dashed lines and open circles). a. Marked stems with Formica ants. b. Marked stems with other ants or abandoned by ants (sample size [Table 1] prevented statistical comparison on the first census). ${ }^{*} P<.05$; ${ }^{* *} P<$ $.01, \mathrm{NS}=$ not significant.

into a leaf and remained there for the entire trial. In the remaining 21 trials, beetles left the release stem by crawling onto overlapping leaves of adjacent stems. Mean beetle duration on stems with small ants or with no ants was $250.7 \mathrm{~s}(\mathrm{SE}=10.8)$, close to the maximum of $300 \mathrm{~s}$ set by trial termination. On stems with Formica ants, beetles usually encountered one or more ants shortly after release. Such contact was likely because beetles and membracids feed and rest in the top one-third of the plant ( $\mathrm{F}$. Messina, personal observation). Beetle detection by one ant often caused nearby ants to cease tending membracids and quickly crawl around the local area of the stem, even along leaf margins and apices. Because membracids are nev-

TABIE 1. Number of marked stems in each category on census dates in 1978 and 1979.

\begin{tabular}{|c|c|c|c|c|c|c|c|c|c|c|c|}
\hline \multirow[b]{2}{*}{ Stem category } & \multicolumn{5}{|c|}{$1978(N=45)$} & \multicolumn{6}{|c|}{$1979(N=36)$} \\
\hline & 30 Jun* & $14 \mathrm{Jul}$ & $28 \mathrm{Jul}$ & 11 Aug & 25 Aug & 31 May & $10 \mathrm{Jun}$ & 19 Jun & $20 \mathrm{Jul}$ & 17 Aug & 22 Sep \\
\hline With Formica antst & 27 & 29 & 33 & 28 & 28 & 33 & 18 & 13 & 6 & 7 & 1 \\
\hline With other ants & 1 & 11 & 7 & 5 & 6 & 3 & 4 & 3 & 6 & 3 & 3 \\
\hline Abandoned & 5 & 5 & 5 & 12 & 11 & 0 & 14 & 20 & 24 & 26 & 32 \\
\hline
\end{tabular}

* On 30 June 1978, $N=33$.

$+F$. fusca alone or with its slave maker, $F$. (Raptiformica) rubicunda.

+ Prenolepis imparis or Myrmica sp. 


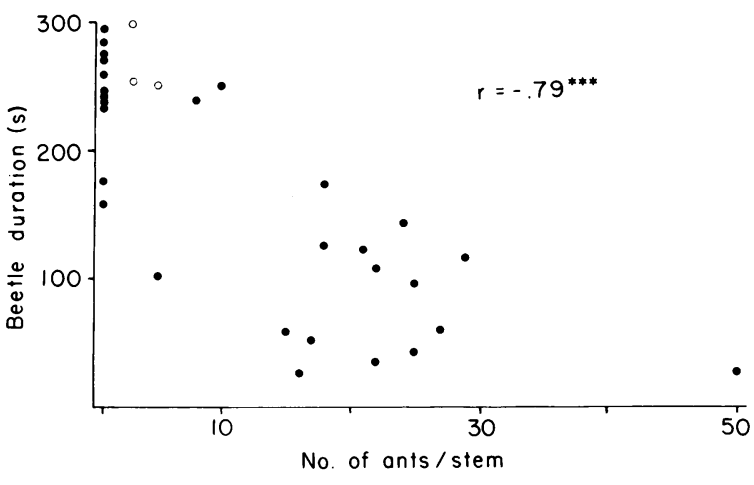

Fig. 3. Relationship between ant density and mean beetle duration on stems in staged encounters. Open circles represent stems with non-Formica ants. ${ }^{* * *} P<.001$.

er found on these plant microsites, this "rapid search" behavior was clearly a response to disturbance. On contact, ants repeatedly lunged at the beetles, attempting to grasp them with their mandibles. Trirhab$d a$ beetles instantly responded to attack by withdrawing their legs and dropping off the stem to the ground below; this defense behavior is typical of adult chrysomelids. If an ant managed to grasp a beetle appendage before the beetle fell off the plant, it would spray the beetle with the tip of its gaster. In these circumstances, beetles continued to struggle and eventually freed themselves and dropped from the plant. In only 12 of 85 trials beetles remained on stems with Formica for the entire trial $(300 \mathrm{~s})$. Although I never observed ants killing or visibly injuring beetles, their aggression was sufficient to reduce mean beetle duration on the stems substantially $(\bar{x}=104.2 \mathrm{~s}, \mathrm{SE}=16.6, P<.01$, $t$ test). The few natural encounters observed between beetles and Formica were similar to the staged encounters.

In addition to the simple reduction in beetle duration due to Formica presence, there was also a negative correlation between the number of Formica ants per stem and beetle duration (Fig. 3; each point represents the mean of five trials on a stem). If all stems (includ-

TABLE 2. Plant characteristics of 26 marked stems bearing Formica ants throughout the season and their nearest unattended neighbors $(\bar{x} \pm \mathrm{SE})$.

\begin{tabular}{|c|c|c|c|}
\hline Plant characteristic & Marked stem & Neighbor & $P$ \\
\hline $\begin{array}{l}\text { Initial height at } \\
30 \text { June or } 14 \text { July } \\
\text { (cm) }\end{array}$ & $91.0 \pm 2.8$ & $69.8 \pm 2.7$ & $<.001 \dagger$ \\
\hline $\begin{array}{l}\text { Seasonal height } \\
\text { increment }(\mathrm{cm})\end{array}$ & $16.5 \pm 2.0$ & $7.0 \pm 2.2$ & $<.001 \dagger$ \\
\hline Number of seeds/stem & $3585 \pm 671$ & $536 \pm 147$ & $<.001 \ddagger$ \\
\hline
\end{tabular}

$\dagger t$ test.

$\ddagger$ Wilcoxon signed-ranks test, due to unequal variances.

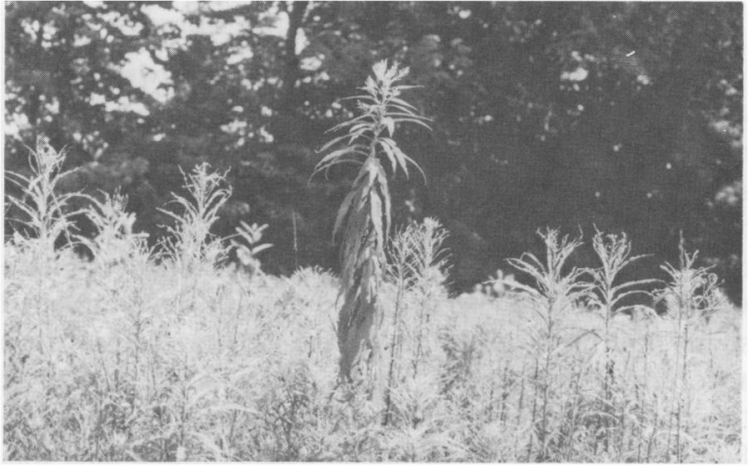

Fig. 4. Comparison of an S. altissima stem with Formica ants (center) and its neighbors from the same clone without ants. Note that membracid oviposition and feeding cause the leaves to become appressed to the stem.

ing those with no ants) are used, the correlation coefficient is $-.79(N=31, P<.001)$. Exclusion of stems without Formica produces a coefficient of $-.45(N=$ $17, P<.05)$. The inverse relationship between ant density and beetle duration would be expected if a greater number of ants corresponded to a shorter time to beetle discovery.

\section{Consequence of Formica presence for the host plant}

Stems with Formica ants differed from their nearest neighbors in several characteristics. Marked stems that bore Formica on all censuses in 1978 were initially taller, grew twice as much in height, and produced nearly seven times as many seeds (Table 2). Because "initial height" in 1978 represented plant height at the time of adult beetle emergence (Fig. 1 and Table 1), the difference in this characteristic suggests some advantage to bearing ants during June, when Trirhabda larvae were abundant. During July and August, Trirhabda adults had a differential impact on stems with or without Formica. For neighboring stems without ants, there was a negative correlation between the number of adult beetles censused per stem and stem height increment $(r=-.52, P<.01)$, but there was no such correlation for stems with Formica. For both groups, height increment, but not initial height, was positively correlated with seed production ( $r=.65$ [with Formica] and $r=.61$ [without Formica], $P<.01$ ). Differences between plants with and without Formica were particularly large in areas of the old field with very high beetle densities; stems with Formica were as much as $50 \mathrm{~cm}$ taller than their neighbors, and could be identified from $100 \mathrm{~m}$ away (Fig. 4).

\section{Relationship between frequency of Formica attendance and plant performance}

Ant abandonment of marked stems in 1979 provided a natural experiment to determine the effect of sea- 


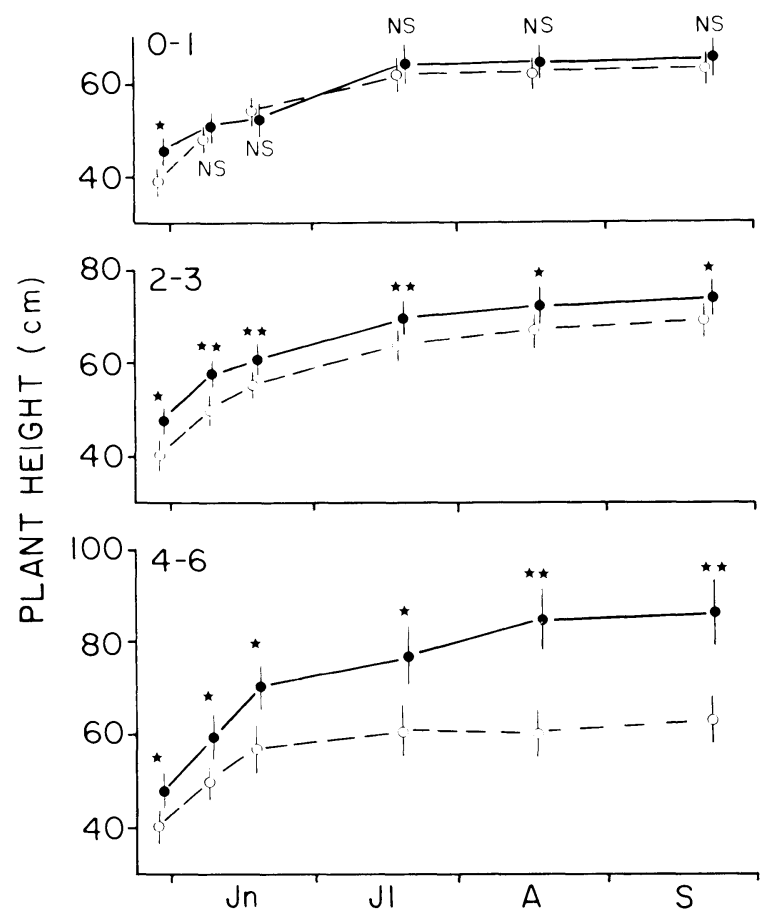

FIc. 5. Relationship between mean plant growth and frequency of Formica attendance. Numbers indicate number of censuses in which Formica was present on marked stems (solid lines and closed circles). Dashed lines and open circles indicate unattended neighbor stems. Vertical lines indicate \pm 1 SE. ${ }^{*} P<.05 ;{ }^{*} P<.01 ;$ NS $=$ not significant.

sonal frequency of ant attendance on plant performance. Marked stems, all of which bore ants in late May, were divided into three categories: infrequent (Formica present on zero or one of the six censuses, $n=11$ ), moderate (Formica present on two or three censuses, $n=18$ ), and frequent attendance (Formica present on four to six censuses, $n=7$ ). In this study, the frequency of attendance is related to the dates of attendance; infrequently tended stems bore Formica only early in the season.

The relationship between frequency of ant attendance and plant growth is shown in Fig. 5. For all three groups, marked stems were initially somewhat taller than their neighbors, suggesting that membracids choose to oviposit on the taller stems. The difference in height on 31 May could not be due to ant behavior, since these stems had just been colonized. While all stems displayed an asymptotic increase in height over the rest of the season, the magnitude of growth was highly dependent on the frequency of ant attendance. During the period of larval Trirhabda abundance, infrequently tended stems quickly converged in height with their nearest neighbors (Fig. 5). Stems tended at moderate frequency remained significantly taller than their neighbors (Wilcoxon signed-ranks test), but the final difference in height was small, indicating partial

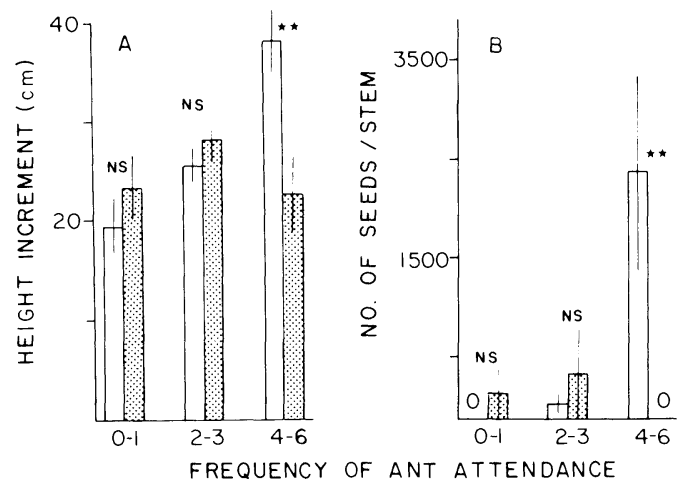

FIG. 6. Relationship between frequency of Formica attendance and total height increment (a) or seed production (b). Numbers indicate number of censuses in which Formica was present on marked stems (open bars). Shaded bars indicate unattended neighbor stems. Vertical lines indicate \pm 1 SE. ${ }^{* *} P<.01 ;$ NS $=$ not significant.

convergence. Finally, frequently tended stems became increasingly taller than their neighbors; the final mean difference in height was $>20 \mathrm{~cm}$. The mean total height increment of frequently tended stems was significantly greater than the total height increment of their neighbors (Fig. 6, $t$ test). Marked stems in the other two categories, however, grew slightly less than their neighbors, again reflecting the partial or complete convergence in height (Fig. 6).

In 1979, unusually high Trirhabda densities prevented most $S$. altissima stems from flowering at Whipple Farm (R. B. Root, personal communication). Flowers were produced by only three of the 29 marked stems that experienced infrequent or moderate attendance, and by only two of the 29 nearest neighbors. Mean seed production by these stems was therefore very low (Fig. 6b). In contrast, five of the seven frequently tended stems flowered, and went on to produce a mean of 2448 seeds/stem $(\mathrm{SE}=1094, n=7)$, compared to zero seed production by their nearest neighbors (Fig. 6). Thus in 1979, Formica presence on stems for most of the season was essentially required for seed production by $S$. altissima.

Although $S$. altissima stems bearing Formica ants for most of 1979 performed much better than their neighbors, such stems exhibited reduced growth relative to stems that experienced no herbivory in that year. R. B. Root (personal communication) used an insecticide spray to protect plants in an adjacent old field at Whipple Farm. While control (unsprayed) stems in that old field were not significantly different in final height from the control ("neighbor") plants described above $(57.8 \pm 2.9 \mathrm{~cm}$ vs. $62.7 \pm 5.1 \mathrm{~cm})$, insecticide-protected plants were taller than "Formica-protected" plants $(114.0 \pm 3.5 \mathrm{~cm}$ vs. $85.7 \pm 5.1$ $\mathrm{cm}, P<.001, t$ test $)$. This suggests that membracids may reduce plant growth in an absolute sense. 
TABle 3. Comparison of Trirhabda larval densities (mean number per stem \pm SE) on stems with Formica ants and on their nearest unattended neighbors.

\begin{tabular}{lcccc}
\hline \hline $\begin{array}{c}\text { Census } \\
\text { date }\end{array}$ & $\begin{array}{c}\text { With Formica } \\
\text { ants }\end{array}$ & Without ants & $\begin{array}{c}\text { Number } \\
\text { pairs }\end{array}$ & $P$ \\
\hline 31 May & $7.5 \pm 0.6$ & $7.5 \pm 0.5$ & 33 & NSt \\
10 June & $8.0 \pm 0.7$ & $8.1 \pm 0.7$ & 18 & NS \\
19 June & $6.0 \pm 0.6$ & $6.2 \pm 0.7$ & 13 & NS \\
\hline$+t$ test. & & & &
\end{tabular}

$+t$ test.

\section{Formica-Trirhabda larvae interactions}

Formica ants encounter Trirhabda larvae for 3-4 wk in June (Fig. 1). Unlike the adults, the sluggish beetle larvae do not drop off the stem when disturbed, so ants would have to push or carry larvae off the stem to remove them. A few casual observations of ants crawling away from membracid aggregations with beetle larvae between their mandibles suggested that larvae might be removed in this way. However, the three larval censuses conducted in 1979 showed that larval densities on stems with Formica were as high as densities on neighboring stems without ants (Table 3 ). If ants do not exclude larvae from the stems, why does plant growth in June suggest some advantage to bearing Formic a at that time (e.g., "initial height" in Table 2, and stem growth in Fig. 5)? One possible explanation is that Formica ants deter larval feeding. This hypothesis was tested in June 1979 by comparing the mean leaf area of 40 stems with Formica to the mean leaf area of their neighbors. Stems with Formica were again taller than their neighbors, contained equal densities of larvae, but sustained much less defoliation (Table 4). The nearly fourfold difference in leaf area is not explained by the difference in height, for while there was a significant linear relationship between stem height and leaf area for both groups, the regression coefficients were significantly different (for stems with Formica, leaf area $=0.20$ height -4.7 ; for neighbors, leaf area $=0.08$ height $-2.3, F$ test for two regression coefficients, $P<.01)$. Thus at a given height, the leaf area of a stem with no ants was significantly lower than the leaf area of a stem with Formica, despite equivalent larval densities. Moreover, the number of Formica ants per stem was positively correlated with the leaf area of the stem and with the difference in leaf area between the stem and its neighbor $(r=.35$ and .42 , respectively, $P<.05)$; the more ants on a stem the greater the difference in leaf area between that stem and its neighbor without ants. In contrast, the difference in height between a stem and its neighbor was not correlated with the difference in leaf area.

Behavioral observations also support the hypothesis of feeding deterrence. Ants frequently bit and sprayed larvae near membracid aggregations. Larvae respond-
TABle 4. Plant characteristics $(\bar{x} \pm \mathrm{SE})$ of 40 randomly located stems with or without Formica ants in June 1979.

\begin{tabular}{lccc}
\hline & $\begin{array}{c}\text { With } \\
\text { Formica } \\
\text { ants }\end{array}$ & $\begin{array}{c}\text { Without } \\
\text { ants }\end{array}$ & $P$ \\
Plant characteristic & $71.3 \pm 1.6$ & $58.0 \pm 1.7$ & $<.001 \dagger$ \\
\hline $\begin{array}{l}\text { Height }(\mathrm{cm}) \\
\text { Number of Trirhab- } \\
\quad d a \text { larvae/stem }\end{array}$ & $4.2 \pm 0.4$ & $4.9 \pm 0.3$ & Ns \\
Leaf area $\left(\mathrm{cm}^{2}\right)$ & $9.6 \pm 0.9$ & $2.6 \pm 0.4$ & $<.001$ \\
\hline$\dagger t$ test. & & &
\end{tabular}

ed to persistent attack by slowly crawling away. In addition, ants sometimes wounded the relatively soft larval cuticle, and dead, moldy larvae were observed on several stems with Formica. The precise mechanism by which ants reduce defoliation remains unknown.

\section{Discussion}

Goldenrod stems with Formica ants escape extensive defoliation by Trirhabda. Plant protection as a by-product of ant-Homoptera interactions has been suggested previously (Carroll and Janzen 1973, Laine and Niemelä 1980, Skinner and Whittaker 1981), and may occur whenever ant-tended Homoptera are not themselves the dominant herbivores of a plant. By expelling non-Homopteran herbivores, ants preserve plant quality for their host Homoptera. This effect has not been included among the known benefits ants provide for their hosts: protection from enemies, transport to feeding sites, facilitation of feeding, and waste removal (Way 1963). In the system described here, however, plant protection may be as important for membracids as protection from natural enemies. In the absence of ants, membracids would have to abandon goldenrod stands with high Trirhabda density, even if their natural enemies were also absent. Defoliation by beetles physically eliminates membracid feeding and oviposition sites on the basal, abaxial surfaces of leaves. Dispersing away from these stands may entail risks associated with finding the patchily distributed ant colonies (McEvoy 1977). By excluding herbivores, ants retain the local Homoptera populations within the relatively fixed foraging area of the colony, and maintain a honeydew supply. Since host plant protection (and probably protection from natural enemies) varies according to ant species (McEvoy 1977), membracids should maximize the probability of being tended by ants at least as large and aggressive as Formica spp. Publilia concava shows certain adaptations that partially support this hypothesis. Females oviposit on stems surrounding Formica mounds, probably because of the low vagility of individuals that succesfully matured in the previous year (McEvoy 1977). Membracid dispersion among stems is highly clumped due to intraspecific attraction among adult females (up to 
seven ovipositing females of Publilia can occur on a single stem [McEvoy 1977]), and due to large egg masses, which establish nymphal aggregations (McEvoy 1979, Wood 1979). These aggregations are preferred by larger ants, such as Formica and Camponotus, which tend to ignore stems with solitary females or small nymphal aggregations (McEvoy 1977). This study demonstrates, however, that ant fidelity is still fairly unpredictable, even on stems near ant mounds (all stems in the censuses were within 5 $m$ of an ant mound).

Ant behavior required to repel phytophagous insects on Homopteran host plants need not be different from ant aggression toward enemies of Homoptera. Ants display an "ownership behavior" (Way 1963, Bentley 1977), a general aggression that may be distinct from predatory behavior, where any arthropod encountered in the foraging route is attacked. Formica fusca ants significantly reduced Trirhabda density on goldenrod, even though this Formica species is a "timid" predator at best (Finnegan 1974). Several ants (e.g., species of Formica in temperate regions) forage from plant nectaries, Homoptera colonies, and lycaenid butterfly larvae (Way 1963, Inouye and Taylor 1979, Pierce and Mead 1981), and probably provide protection with similar behavior in each case. Bentley (1976) achieved some reduction in herbivory by simply baiting bean plants with sugar droplets; this suggests that ants need no behavioral cue from their hosts to display aggression while gathering sugar. The results presented here support the proposition that any aggression may be useful in the biological control of insect pests, despite the accompanying increase in Homoptera densities (Gösswald 1954, Finnegan 1974; but see Laine and Niemelä 1980, Skinner and Whittaker 1981). Nickerson et al. (1977) found that the presence of membracid nymphs on soybean significantly increased ant predation on the eggs of a soybean pest species.

The different outcomes of Formica encounters with Trirhabda larvae and adults may be understood in relation to the energy expenditure required to remove each stage. Adult beetles are quickly repelled, and are more likely to be detected because of their more frequent and more rapid movement (Way 1963). In June, ants usually encounter the sluggish, third- (last-) instar beetle larvae, which greatly outweigh ant foragers. In a similar situation, El-Ziady and Kennedy (1956) observed that workers of the common garden ant, Lasius niger, quickly repelled adult coccinellids from aphid $\rightarrow$ aggregations and carried off small coccinellid larvae, but mature larvae were not carried; these larvae gradually moved away after repeated aggression. On goldenrod, Formica ants may drive Trirhabda larvae away from membracid aggregations by persistent attack.

While plant protection seems to be an extension of the ant-Homoptera mutualism, and is not strictly fortuitous, this phenomenon should not be interpreted as an evolutionarily beneficial relationship between membracids and goldenrod (in the sense of an "indirect mutualism" [Vandermeer 1980]). In goldenrod stands with few or no beetles, plants with the phloemfeeding membracid colonies may be at a relative disadvantage. Membracid feeding and oviposition cause goldenrod leaves to senesce prematurely and become appressed to the stem (Fig. 4), possibly reducing photosynthetic capacity. Unlike plants in typical ant-plant mutualisms, goldenrods possess no adaptations to attract membracids and accompanying ants. Even though ants exclude herbivores from homopteran host plants, they significantly increase the negative impact of the Homoptera themselves, by increasing Homoptera density and feeding rates (Carroll and Jansen 1973). In general, membracid impact on Solidago is probably quite variable, depending on the density of Trirhabda or other important herbivores. This variability suggests that community analyses based simply on the pairwise, first-order interactions of the component species may be inadequate (Neill 1974, Lawlor 1979). Studies of the isolated (pairwise) interactions among goldenrod, membracids, ants, and leaf beetles would not be sufficient to predict the impact on the plant in the presence of all species. While previous studies of indirect effects of multispecies interactions have been concerned with competition (e.g., Neill 1974), the data presented here indicate that these interactions may be important in predator-prey (i.e., herbivore-host plant) systems as well. Further studies of multispecies interactions, particularly in component communities (Root 1973), may reveal that higher order effects are important determinants of community structure.

\section{ACKNOWIEDGMENTS}

I thank R. B. Root, G. C. Eickwort, P. Kareiva, and S. Kinsman for comments on the manuscript, G. Schakaraschwili and R. Wetzler for field assistance, and C. Kugler for identifying the ants. I also benefited from discussions with the Comparative Ecology Guild (late 70's cohort) at Cornell. This research was supported by NSF Grant DEB 77-25120 to R. B. Root.

\section{Literature Cited}

Bentley, B. L. 1976. Plants bearing extrafloral nectaries and the associated ant community: interhabitat differences in the reduction of herbivore damage. Ecology 54:815-820.

$\longrightarrow \rightarrow$. 1977. Extrafloral nectaries and protection by pugnacious bodyguards. Annual Review of Ecology and Systematics 8:407-427.

Carroll, C. R., and D. H. Janzen. 1973. Ecology of foraging by ants. Annual Review of Ecology and Systematics 4:231257.

$\rightarrow$ El-Ziady, S., and J. S. Kennedy. 1956. Beneficial effects of the common garden ant, Lasius niger L., on the black bean aphid, Aphis fabae Scopoli. Proceedings of the Royal Entomological Society of London (A) 31:61-65.

Evans, E. W. 1980. Lifeways of predatory stinkbugs: feeding and reproductive patterns of a generalist and specialist (Pentatomidae: Podisus maculiventris and Perillus circum(inctus). Dissertation. Cornell University, Ithaca, New York, USA. 
Finnegan, R. J. 1974. Ants as predators of forest pests. En $\rightarrow$ Neill, W. E. 1974. The community matrix and the interdetomophaga 7:53-59.

Gösswald, K. 1954. Über die Wirtschaftlichkeit des Maspendence of competition coefficients. American Naturalist 108:399-408.

seneinsatzes der Roten Waldameise. Zeitschrift für Ange $\rightarrow$ Nickerson, J. C., C. A. Rolph Kay, L. L. Buschman, and wandte Zoologie 41:145-185.

$\rightarrow$ Inouye, D. W., and O. R. Taylor, Jr. 1979. A temperate region plant-ant-seed predator system: consequences of extra floral nectar secretion by Helianthella quinquenervis. Ecology 60:1-7.

$\rightarrow$ Janzen, D. H. 1966. Coevolution of mutualism between ants and acacias in Central America. Evolution 20:249-275.

1967. Interaction of the bull's-horn acacia (Acacia cornigera L.) with an ant inhabitant (Pseudomyrmex ferruginea F. Smith) in Eastern Mexico. University of Kansas Science Bulletin 47:315-558.

$\rightarrow$ Laine, K. J., and P. Niemelä. 1980. The influence of ants on the survival of mountain birches during an Oporinia autumnata (Lep., Geometridae) outbreak. Oecologia 47:39-42.

$\rightarrow$ Lawlor, L. R. 1979. Direct and indirect effects on n-species competition. Oecologia 43:355-364.

McEvoy, P. B. 1977. Adaptive significance of clumped dispersion in a treehopper, Publilia concava (Homoptera: Membracidae). Dissertation. Cornell University, Ithaca, New York, USA.

- 1979. Advantages and disadvantages to group living in treehoppers (Homoptera: Membracidae). Miscellaneous Publication of the Entomological Society of America 11:113.

Messina, F. J., and R. B. Root. 1980. The association between leaf beetles and meadow goldenrods (Solidago spp.) in central New York. Annals of the Entomological Society of America 73:641-646.

$\rightarrow$ Nault, L. R., M. E. Montgomery, and W. S. Bowers. 1976. Ant-aphid association: role of aphid alarm pheromone. Science 192: 1349-1351. W. H. Whitcomb. 1977. The presence of Spissistilus festinus as a factor affecting egg predation by ants in soybeans. Florida Entomologist 60:193-199.

$\rightarrow$ Pierce, N. E., and P. S. Mead. 1981. Parasitoids as selective agents in the symbiosis between lycaenid butterfly larvae and ants. Science 211:1185-1187.

Rehr, S. S., P. P. Feeny, and D. H. Janzen. 1973. Chemical defense in Central American non-ant-acacias. Journal of Animal Ecology 42:405-416.

$\rightarrow$ Root, R. B. 1973. Organization of a plant-arthropod association in simple and diverse habitats: the fauna of collards (Brassica oleracea). Ecological Monographs 43:95-124.

$\rightarrow$ Skinner, G. J., and J. B. Whittaker. 1981. An experimental investigation of inter-relationships between the wood-ant (Formica rufa) and some tree-canopy herbivores. Journal of Animal Ecology 50:313-326.

$\rightarrow$ Tilman, D. 1978. Cherries, ants and tent caterpillars: timing of nectar production in relation to susceptibility of cater-

pillars to ant predation. Ecology 59:686-692.
$\rightarrow$ Vandermeer, J. 1980. Indirect mutualism: variations on a theme by Stephen Levine. American Naturalist 116:441448.

Way, M. J. 1963. Mutualism between ants and honeydewproducing Homoptera. Annual Review of Entomology 8:307-344.

Wood, T. K. 1977. Role of parent females and attendant ants in maturation of the treehopper, Entylia bactriana (Homoptera: Membracidae). Sociobiology 2:257-272.

. 1979. Sociality in the Membracidae (Homoptera).

Miscellaneous Publications of the Entomological Society of America 11:15-22. 